Full paper

\title{
Boosting photoelectrochemical activities of heterostructured photoanodes through interfacial modulation of oxygen vacancies
}

\author{
Xiaoqiang An ${ }^{\mathrm{a}}$, Le Zhang ${ }^{\mathrm{b}}$, Bo Wen ${ }^{\mathrm{b}}$, Zhenao Gu ${ }^{\mathrm{a}, \mathrm{d}}$, Li-Min Liu ${ }^{\mathrm{b}, * *}$, Jiuhui Qu ${ }^{\mathrm{a}, \mathrm{d}}$, Huijuan Liu ${ }^{\mathrm{c}, \mathrm{d}, *}$ \\ ${ }^{a}$ Key Laboratory of Drinking Water Science and Technology, Research Center for Eco-Environmental Sciences, Chinese Academy of Sciences, Beijing \\ 100085, China \\ b Beijing Computational Science Research Center, Beijing 100193, China \\ c State Key Laboratory of Environmental Aquatic Chemistry, Research Center for Eco-Environmental Sciences, Chinese Academy of Sciences, Beijing 100085, \\ China \\ d University of Chinese Academy of Sciences, Beijing 100049, China
}

\section{A R T I C L E I N F O}

\section{Keywords:}

Photoelectrochemical

Photoanodes

Interfacial structure

Oxygen vacancy

Defect distribution

\begin{abstract}
A B S T R A C T
Oxygen deficiency control has become an on-looming strategy for improving the catalytic ability of semiconductors, while the impact of defect distribution on the separation of charge carriers is still an open question. Herein, $\mathrm{TiO}_{2} / \mathrm{Bi}_{2} \mathrm{WO}_{6}$ heterostructures are used as a typical model to demonstrate the hypothesis of boosting photoactivity of photoanodes through modulating the spatial distribution of oxygen vacancies. Compared to pristine $\mathrm{TiO}_{2}$, significantly improved photoelectrochemical performance is achieved through suppressing intrinsic defects in $\mathrm{Bi}_{2} \mathrm{WO}_{6}$ and tuning the formation sites of interfacial oxygen vacancies. Both experimental and theoretical investigations demonstrate that the distribution of interfacial oxygen vacancies around interface of $\mathrm{Bi}_{2} \mathrm{WO}_{6}$ and in the $\mathrm{TiO}_{2}$ side is beneficial for the efficient extraction of photogenerated electrons toward counter electrodes. This research shed atomic-level insight into the interfacial modulation of defect distribution. Therefore, it provides a new principle to develop efficient heterostructures for photoelectrochemical and photocatalytic applications.
\end{abstract}

\section{Introduction}

Photoelectrochemical (PEC) is widely considered as a promising way to mitigate environmental issues caused by the combustion of fossil fuels and to meet increasing worldwide demands for energy. By far, the major limiting factors affecting the performance of photoelectrodes include light absorption, charge separation and surface reactions [1,2]. Substantial efforts have been put into solving these problems, while the construction of heterostructured photoanodes is one of the most effective strategies. Over the past decades, many different types of heterostructures have been designed and extensively studied, such as type-I, type-II (staggered alignment), Z-scheme system and $\mathrm{p}-\mathrm{n}$ junctions [3-5]. However, it still remains a great challenge to overcome the limitation of charge extraction for potential industrial applications. This is largely caused by the complicated interfacial mechanism, involving the formation of structural defects, strain field, surface states, etc. [6,7]. Especially, it is of both scientific and technical importance to evaluate the effect of interfacial structures on the PEC performance at the atomic-level $[8,9]$.
Due to the significant impact on material properties ranging from ionic conductivity, charge localization to surface reactivity, defect modulation has become one of the most promising emerging strategies for developing highefficiency photocatalysts $[10,11]$. Tremendous studies demonstrate that oxygen vacancy $\left(\mathrm{O}_{\mathrm{v}}\right)$ states can remarkably affect the surface adsorption and reactivity of semiconductors [12-14]. Importantly, our recent study indicates that unpredictable activities of controversial heterojunctions is essentially dependent with the spontaneous formation of interfacial oxygen vacancies $[15,16]$. From the perspective of interfacial modulation, the comprehensive investigation of creation, migration, aggregation and distribution of oxygen vacancies is prerequisites for establishing the full picture of defective structures of heterostructures. Unfortunately, most prevailing strategies of defect modulation focus on the macroscopic characteristics of oxygen vacancies around heterostructured interfaces [17]. The impact of spatial distribution of oxygen vacancies on the separation of photogenerated charge carriers is still an open question [18]. Nevertheless, the orders-of-magnitude enhanced electrical conduction in non-stoichiometric heterostructures demonstrates the great potential of

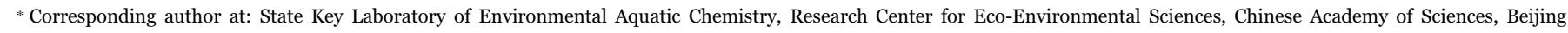
100085, China.

** Co-corresponding author at: Beijing Computational Science Research Center, Beijing 100094, China.

E-mail addresses: limin.liu@csrc.ac.cn (L.-M. Liu), hjliu@rcees.ac.cn (H. Liu). 
oxygen-deficiency modulation for emergent behavior [19].

Taking these facts into consideration, we unveiled a principle of boosting PEC activities of photoanodes through atomic-level modulation of interfacial oxygen vacancies. $\mathrm{TiO}_{2} / \mathrm{Bi}_{2} \mathrm{WO}_{6}$ heterostructured interfaces was selected as a prototypical example to demonstrate the fundamental impacts of intrinsic defects and spontaneously formed interfacial oxygen vacancies on the charge separation behaviors. Both experimental observations and theoretical calculations demonstrated that significantly improved photoactivity could be achieved through suppressing the formation of intrinsic defects in $\mathrm{W}-\mathrm{O}-\mathrm{W}$ coordination layer and simultaneously modulating the spatial distribution of interfacial oxygen vacancies. The separation of charge carriers in the heterostructures was greatly facilitated through controlling the spontaneous formation of vacancies around the interface of $\mathrm{Bi}_{2} \mathrm{WO}_{6}$ and in the $\mathrm{TiO}_{2}$ side. This simple and effective strategy provides new and unexplored opportunity of defect modulation by controlling oxygen stoichiometry, for high-efficiency photoelectrochemical and photocatalytic applications.

\section{Experimental section}

\subsection{Synthesis of $\mathrm{Bi}_{2} \mathrm{WO}_{6}$ with controlled oxygen vacancies}

A facile glycol-assisted solvothermal method was used to fabricate $\mathrm{Bi}_{2} \mathrm{WO}_{6}$ photocatalysts with different concentration of oxygen vacancies. In a typical synthesis, $0.4 \mathrm{mmol}$ of $\mathrm{Bi}\left(\mathrm{NO}_{3}\right)_{3} \cdot 5 \mathrm{H}_{2} \mathrm{O}$ was dissolved in $25 \mathrm{~mL}$ of ethylene glycol in a Teflon-lined autoclave. The solution was sonicated for $5 \mathrm{~min}$, then $0.2 \mathrm{mmol}$ of $\mathrm{Na}_{2} \mathrm{WO}_{4} \cdot 2 \mathrm{H}_{2} \mathrm{O}$ was added. The concentration of oxygen vacancies in $\mathrm{Bi}_{2} \mathrm{WO}_{6}$ products could be well controlled by changing the mixing conditions of the reaction solution. For lower concentration of oxygen vacancies, the suspension was stirred for $30 \mathrm{~min}$ at room temperature and then heated at $160^{\circ} \mathrm{C}$ for $15 \mathrm{~h}$. An additional ultrasonic process was adopted to facilitate the formation of oxygen vacancies, as the concentration increased along with the prolonged sonication time. Finally, the products were collected by centrifuging, washed with deionized water thoroughly and dried at $60{ }^{\circ} \mathrm{C}$. For the convenience of descriptions, $\mathrm{Bi}_{2} \mathrm{WO}_{6}$ with low, medium and high concentration of oxygen vacancies were denoted as $\mathrm{L}^{-} \mathrm{O}_{\mathrm{v}}$ $\mathrm{Bi}_{2} \mathrm{WO}_{6}, \mathrm{M}-\mathrm{O}_{\mathrm{v}}-\mathrm{Bi}_{2} \mathrm{WO}_{6}$ and $\mathrm{H}-\mathrm{O}_{\mathrm{v}}-\mathrm{Bi}_{2} \mathrm{WO}_{6}$, respectively.

\subsection{Fabrication of $\mathrm{TiO}_{2} / \mathrm{Bi}_{2} \mathrm{WO}_{6}$ heterostructures}

To construct heterostructured interfaces between $\mathrm{TiO}_{2}$ and $\mathrm{Bi}_{2} \mathrm{WO}_{6}$, rutile $\mathrm{TiO}_{2}\left(\mathrm{R}-\mathrm{TiO}_{2}\right)$ and rutile/anatase $\mathrm{TiO}_{2}\left(\mathrm{R} / \mathrm{A}-\mathrm{TiO}_{2}\right)$ were synthesized using a hydrothermal method described in our previous paper [16]. Then, FTO substrate coated with different types of $\mathrm{TiO}_{2}$ films were placed at an angle against the wall of the Teflon-liner. During the subsequent solvothermal treatment, similar reaction conditions were used to deposit $\mathrm{Bi}_{2} \mathrm{WO}_{6}$ with different concentration of oxygen vacancies onto $\mathrm{TiO}_{2}$.

\subsection{Characterizations}

X-Ray diffraction (XRD) was performed using a Rigaku RINT 2100, with a voltage of $40 \mathrm{kV}$. The morphologies of the products were characterized by field emission scanning electron microscope (FESEM, JSM-7600F, JEOL) and high-resolution transmission electron microscope (HR-TEM, JEOL-2010). The elemental composition of films was examined by energy dispersive X-ray spectrometer (EDS). X-ray photoelectron spectroscopy (XPS) was carried out using the XPS spectrometers (ESCALab220I-XL). The diffuse reflectance spectra were characterized by UV-vis-NIR spectrophotometer (Cary 5000). Electron spin resonance (ESR) analysis was operated at a Bruker E500 spectrometer.

\subsection{Evaluation of photocatalytic activities}

Photoactivity of $\mathrm{Bi}_{2} \mathrm{WO}_{6}$ with different concentration of oxygen vacancies was evaluated by the photocatalytic degradation of $\mathrm{RhB}$, with a $300 \mathrm{~W}$ Xe lamp as light source. Typically, $10 \mathrm{mg}$ of photocatalysts were dispersed in the dye solution $(50 \mathrm{~mL}, 10 \mathrm{ppm})$ in a cylindrical vessel under magnetic stirring. The suspension was stirred in the dark for $2 \mathrm{~h}$ before irradiation to ensure the adsorption-desorption equilibrium. Certain amount of suspension was sampled every $15 \mathrm{~min}$ by micropore filtration membranes for the subsequent measurement. The concentrations of filtrates were analyzed using a UV-Vis spectrophotometer (Hitachi UV-3100).

\subsection{Photoelectrochemical measurements}

Electrochemical and photoelectrochemical measurements were performed using a three-electrode configuration. $\mathrm{TiO}_{2}$-based heterstructures were used as working electrode, with $\mathrm{Ag} / \mathrm{AgCl}$ as reference and Pt plate as counter electrode. For PEC studies, $0.2 \mathrm{M} \mathrm{Na}_{2} \mathrm{SO}_{4}$ aqueous solution was used as electrolyte. The tests were carried out using a $150 \mathrm{~W}$ Xe lamp equipped with $\mathrm{AM} 1.5 \mathrm{G}$ filter, with light intensity of $100 \mathrm{~mW} \mathrm{~cm}^{-2}$. Photocurrent was measured by linearsweep voltammetry (Gamry electrochemical workstation, Interface 1000). The electrical impedance spectroscopic (EIS) and MottSchottky plots at a frequency of $1000 \mathrm{~Hz}$ were measured in the dark.

\subsection{First-principles calculations}

The density functional theory (DFT) calculation was performed by applying CP2K/Quickstep package [20]. The PBE exchange correlation functional was used for all calculations. Hubbard $\mathrm{U}$ correction was applied to $\mathrm{W} 5 \mathrm{~d}$ and Ti $3 \mathrm{~d}$ orbitals with the corresponding $\mathrm{U}$ values set to $5 \mathrm{eV}$ and $4.2 \mathrm{eV}$, respectively [21,22]. The norm-conserving Goedecker, Teter, and Hutter (GTH) pseudo potentials were used to describe core electrons [23]. The wave function of valence electrons were expanded in terms of Gaussian function with molecularly optimized double-zeta polarized basis sets (m-DZVP) [24]. A 320 Ry cut off energy was used for auxiliary basis set of plane waves.

With a perovskite-like layered structure, $\mathrm{Bi}_{2} \mathrm{WO}_{6}-(010)$ are usually selected as typical exposed facets for structural simulation. Accordingly, $\mathrm{A}-\mathrm{TiO}_{2} / \mathrm{Bi}_{2} \mathrm{WO}_{6}$ heterostructures were modeled by four layers of anatase(101) and twelve layers of $\mathrm{Bi}_{2} \mathrm{WO}_{6}-(010)$. $\mathrm{R}-\mathrm{TiO}_{2} / \mathrm{Bi}_{2} \mathrm{WO}_{6}$ heterostructures were modeled by four layers of rutile-(110) and twelve layers of $\mathrm{Bi}_{2} \mathrm{WO}_{6}-(010)$.

\section{Results and discussion}

\subsection{Modulation of intrinsic defects of $\mathrm{Bi}_{2} \mathrm{WO}_{6}$}

Photoactivity of heterostructures is highly dependent on the electronic structures of component semiconductors. To demonstrate the strategy of interfacial modulation, $\mathrm{TiO}_{2}$ and $\mathrm{Bi}_{2} \mathrm{WO}_{6}$, typical semiconductors with finely tuned electronic structures, were selected as model photocatalysts. A facile glycol-assisted solvothermal method was used to modulate intrinsic oxygen vacancies in $\mathrm{Bi}_{2} \mathrm{WO}_{6}$, by changing mixing conditions of precursor solution (Fig. S1). Fig. 1a and Fig. S2 show the SEM images of $\mathrm{Bi}_{2} \mathrm{WO}_{6}$ prepared from precursor solutions with or without ultrasonic treatment, respectively. Both samples possess the morphology of flow-like superstructures assembled by 2-D nanoplates. XRD patterns in Fig. S3 reveal that all of the samples are consisted of orthorhombic phase of $\mathrm{Bi}_{2} \mathrm{WO}_{6}$ (JCPDS No. 79-2381).

The effect of fabrication conditions on the electronic structure of $\mathrm{Bi}_{2} \mathrm{WO}_{6}$ were studied by XPS. In the high resolution $\mathrm{W} 4 \mathrm{f}$ spectrum of $\mathrm{L}-\mathrm{O}_{\mathrm{v}}-\mathrm{Bi}_{2} \mathrm{WO}_{6}$ (Fig. 1b), the two bands at 37.4 and $35.3 \mathrm{eV}$ are ascribed to $\mathrm{W} 4 \mathrm{f}_{7 / 2}$ and $\mathrm{W} 4 \mathrm{f}_{5 / 2}$ of $\mathrm{W}^{6+}$. Differently, the core-level spectrum of 

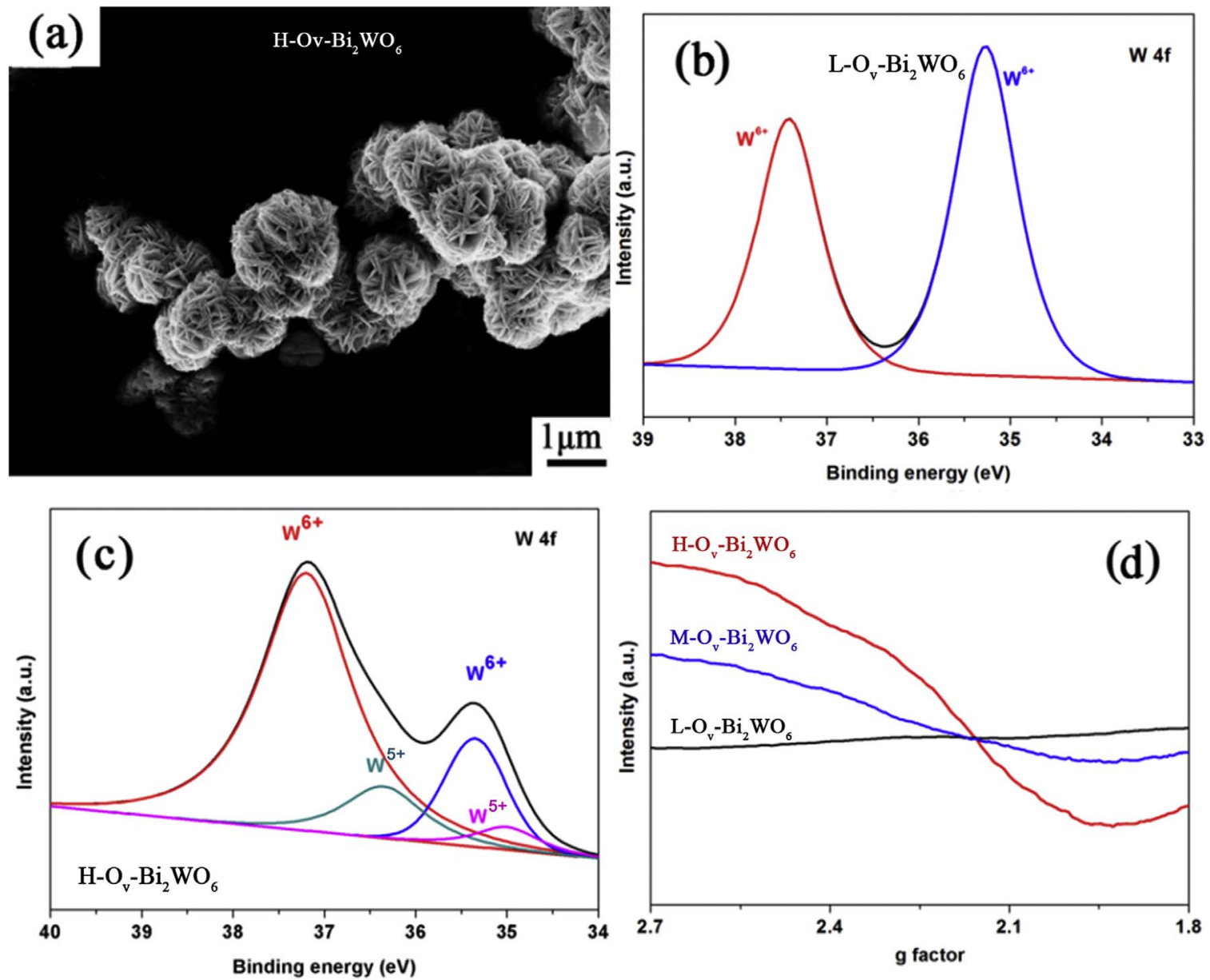

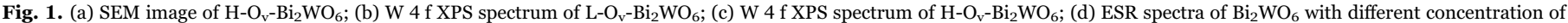
oxygen vacancies.

$\mathrm{H}-\mathrm{O}_{\mathrm{v}}-\mathrm{Bi}_{2} \mathrm{WO}_{6}$ can be fitted into spin-orbit doublets (Fig. 1c). The appearance of +5 oxidation state of $\mathrm{W}$ at 36.3 and $35.0 \mathrm{eV}$ indicates the change of electronic structures [25]. The formation of oxygen vacancyrelated species can be confirmed by the significant change of $\mathrm{O} 1 \mathrm{~s}$ spectra in Fig. S4a [26]. ESR spectra can further elucidate the defective structure of $\mathrm{Bi}_{2} \mathrm{WO}_{6}$ photocatalysts. In Fig. $1 \mathrm{~d}, \mathrm{H}-\mathrm{O}_{\mathrm{v}}-\mathrm{Bi}_{2} \mathrm{WO}_{6}$ with ultrasonic treatment exhibits much stronger ESR signal than that with mild stirring $\left(\mathrm{L}-\mathrm{O}_{\mathrm{v}}-\mathrm{Bi}_{2} \mathrm{WO}_{6}\right)$. The intensity of broad signal in the region of $g=1.9-2.3$ increases with prolonged treatment time, which can be ascribed to the formation of abundant oxygen-centered surface hole trapping sites generated by oxygen vacancies [27]. These results strongly support that successful modulation of oxygen vacancy defects in $\mathrm{Bi}_{2} \mathrm{WO}_{6}$ by changing treatment method of reaction precursors.

To better understand the intrinsic nature of defects, the possible formation sites of oxygen vacancies in $\mathrm{Bi}_{2} \mathrm{WO}_{6}$ were evaluated by firstprinciples calculations. As one of the simplest member of Aurivillius family, $\mathrm{Bi}_{2} \mathrm{WO}_{6}$ with a layered structure is composed of perovskite-like slabs of $\left[\mathrm{WO}_{4}\right]^{2-}$ sandwiched between $\left(\mathrm{Bi}_{2} \mathrm{O}_{2}\right)^{2+}$ units [28]. DFT calculation was utilized to calculate the formation energies of $\mathrm{O}_{v}$ in different coordination sites, using a $3 \times 1 \times 3$ supercell. The $\mathrm{O}_{\mathrm{v}}$ formation energy is calculated by equation: $E_{f}=E_{\text {defect }}+u_{o}-E_{\text {perfect }}$, where the $E_{f}$, $E_{\text {defect }}, u_{o}$ and $E_{\text {perfect }}$ represent the $\mathrm{O}_{v}$ formation energy, total energy of defect structures, oxygen chemical potential and total energy of perfect structures, respectively. The relatively small $\mathrm{O}_{\mathrm{v}}$ formation energies indicate the easy formation of defects in $\mathrm{Bi}_{2} \mathrm{WO}_{6}$ during solvothermal reactions. The relative energy and $\mathrm{O}_{\mathrm{v}}$ formation energy of different defective sites in $\mathrm{Bi}_{2} \mathrm{WO}_{6}$ are shown in Table 1 . Bi-O-Bi and $\mathrm{W}-\mathrm{O}-\mathrm{W}$ are determined to be the most stable sites for $\mathrm{O}_{\mathrm{v}}$ formation, with similar calculated values. In contrast, $\mathrm{O}_{\mathrm{v}}$ formation energy in $\mathrm{Bi}-\mathrm{O}-\mathrm{W}$ is
Table 1

Relative energy and $\mathrm{O}_{\mathrm{v}}$ formation energy of defect structures.

\begin{tabular}{lll}
\hline $\mathrm{O}_{\mathrm{v}}$ site & Relative energy $(\mathrm{eV})$ & Formation energy $(\mathrm{eV})$ \\
\hline $\mathrm{Bi}-\mathrm{O}-\mathrm{Bi}$ & 0.00 & 3.00 \\
$\mathrm{~W}-\mathrm{O}-\mathrm{W}$ & 0.05 & 3.05 \\
$\mathrm{Bi}-\mathrm{O}-\mathrm{W}$ & 1.18 & 4.23 \\
\hline
\end{tabular}

much higher $(4.23 \mathrm{eV})$, indicating the unfavorable formation of intrinsic defects in this layer (Table 1 ).

The electronic structure and spin density of the highest occupied molecular orbitals of $\mathrm{Bi}_{2} \mathrm{WO}_{6}$ with $\mathrm{O}_{\mathrm{v}}$ in the $\mathrm{W}-\mathrm{O}-\mathrm{W}$ and $\mathrm{Bi}-\mathrm{O}-\mathrm{Bi}$ coordination layers were calculated. For the former case, the defect states are mainly composed of $\mathrm{W}$, indicating that electrons released by oxygen vacancies are captured by $\mathrm{W}$ atoms in the $\left[\mathrm{WO}_{4}\right]^{2-}$ layers. The generation of $\mathrm{O}_{\mathrm{v}}$ in the $\mathrm{Bi}-\mathrm{O}-\mathrm{Bi}$ layer exhibits different impact on the electronic structure of $\mathrm{Bi}_{2} \mathrm{WO}_{6}$, as electrons released by oxygen vacancies are mainly distributed on $\mathrm{Bi}$ atoms. Note that no obvious change of $\mathrm{Bi} 4 \mathrm{f}$ peaks is seen in Fig. S4b, indicating the preferential formation of oxygen vacancies in $\mathrm{W}-\mathrm{O}-\mathrm{W}$ layers.

The impact of oxygen vacancy formation on the light absorption ability of $\mathrm{Bi}_{2} \mathrm{WO}_{6}$ was evaluated. In the DRS spectra (Fig. 2a), both $\mathrm{L}-\mathrm{O}_{\mathrm{v}}-\mathrm{Bi}_{2} \mathrm{WO}_{6}$ and $\mathrm{H}-\mathrm{O}_{\mathrm{v}}-\mathrm{Bi}_{2} \mathrm{WO}_{6}$ exhibit strong absorption in the visible light region, with similar absorption edges around $450 \mathrm{~nm}$. Differently, $\mathrm{Bi}_{2} \mathrm{WO}_{6}$ with high concentration of oxygen vacancies shows broad absorption tail in the wavelength range of $450-800 \mathrm{~nm}$. The obviously extended absorption towards to near infrared region implies the existence of trap states induced by oxygen vacancies [29]. Accordingly, the color of $\mathrm{Bi}_{2} \mathrm{WO}_{6}$ powders 

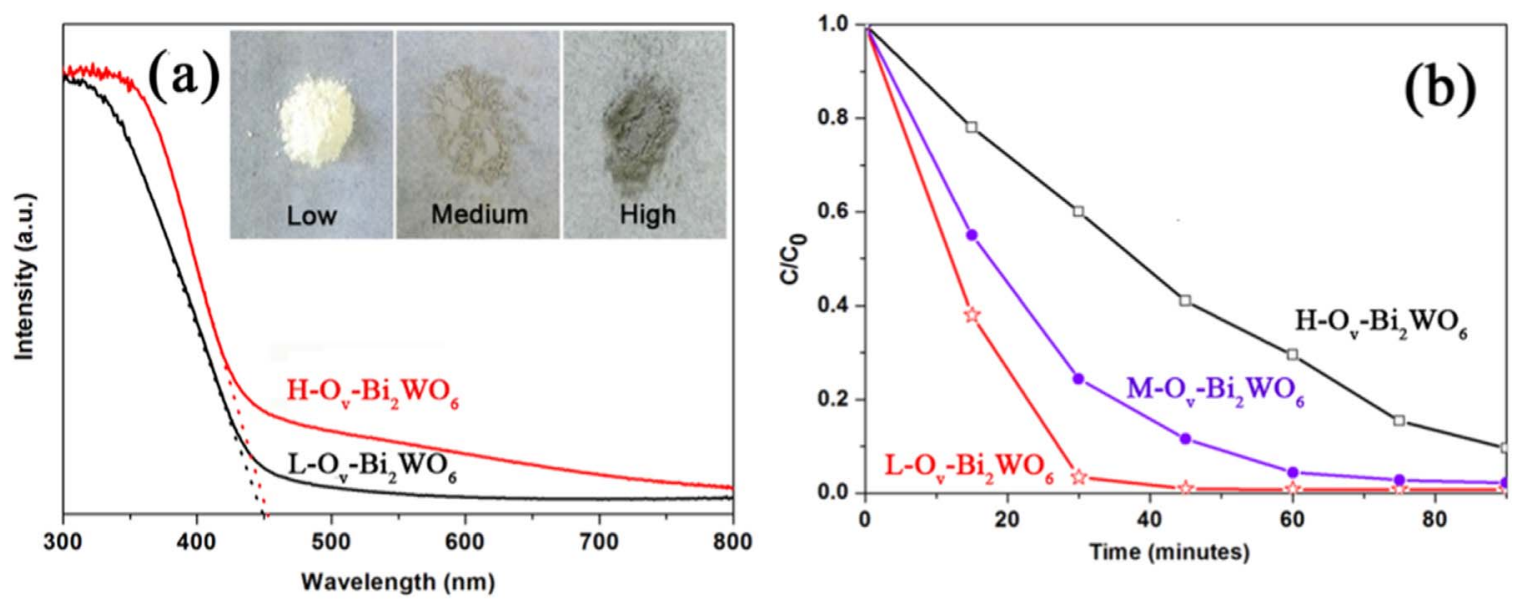

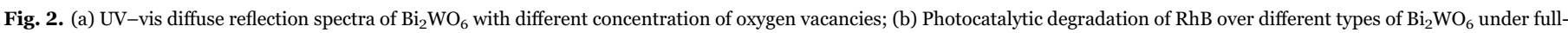
arc irradiation.

changes from white to dark-gray, accompanied with the gradual formation of non-stoichiometric structures.

Rhodamine $\mathrm{B}(\mathrm{RhB})$ was used as a model pollutant to evaluate the photocatalytic activity of $\mathrm{Bi}_{2} \mathrm{WO}_{6}$ with modulated intrinsic defects. As shown in Fig. 2b, photoactivity of $\mathrm{Bi}_{2} \mathrm{WO}_{6}$ is highly dependent with the concentration of oxygen vacancies, as $\mathrm{L}-\mathrm{O}_{\mathrm{v}}-\mathrm{Bi}_{2} \mathrm{WO}_{6}$ presents 4 times higher apparent rate constant than $\mathrm{H}-\mathrm{O}_{\mathrm{v}}-\mathrm{Bi}_{2} \mathrm{WO}_{6}$. It indicates that oxygen vacancies in the $\left[\mathrm{WO}_{4}\right]^{2-}$ layers is detrimental for the full spectrum activity of photocatalysts, although the intermediate state absorption contributes to the superior charge mobility and nearinfrared photoactivities (Fig. S5a) [30]. This effect can be well interpreted by the defect-dependent formation of surface reactive species. It has been reported that oxygen molecular activation can be facilitated by oxygen deficiency, which agrees well with the enhanced oxygen reduction property of $\mathrm{H}-\mathrm{O}_{\mathrm{v}}-\mathrm{Bi}_{2} \mathrm{WO}_{6}$ compared to $\mathrm{L}-\mathrm{O}_{\mathrm{v}}-\mathrm{Bi}_{2} \mathrm{WO}_{6}$ (Fig. S6). Therefore, formation of superoxide radicals should be favorable for $\mathrm{H}-\mathrm{O}_{\mathrm{v}}-\mathrm{Bi}_{2} \mathrm{WO}_{6}$ under illumination, whereas nonradiative relaxation in the defective structures inevitably decreases the oxidation ability of photogenerated holes [31]. Noted that holes are determined to be the dominant reactive species for degradating $\mathrm{RhB}$ (Fig. $\mathrm{S} 5 \mathrm{~b}$ ), it is reasonable that deteriorated photoactivity is achieved for $\mathrm{Bi}_{2} \mathrm{WO}_{6}$ with oxygen vacancies in $\mathrm{W}-\mathrm{O}-\mathrm{W}$ coordination sites. Therefore, the facile modulation of intrinsic defects of component semiconductors is a prerequisite for designing efficient heterostructured photoanodes.

\subsection{Modulation of interfacial oxygen vacancies of heterostructures}

To reveal the fundamental role of oxygen vacancy distribution for interfacial charge separation, $\mathrm{Bi}_{2} \mathrm{WO}_{6}$ with modulated intrinsic defects was used to construct $\mathrm{TiO}_{2} / \mathrm{Bi}_{2} \mathrm{WO}_{6}$ heterostructures. XRD patterns of $\mathrm{TiO}_{2} / \mathrm{Bi}_{2} \mathrm{WO}_{6}$ are presented in Fig. 3a, distinct peaks at $2 \theta=37.1,63.7$ and $70.7^{\circ}$ can be indexed to tetragonal phase of rutile $\mathrm{TiO}_{2}\left(\mathrm{R}-\mathrm{TiO}_{2}\right.$, JCPDS No. 88-1175). The formation of orthorhombic $\mathrm{Bi}_{2} \mathrm{WO}_{6}$ is confirmed by the appearance of new diffraction peaks around $34.5^{\circ}$ and $42.4^{\circ}$. According to SEM observations (Fig. $3 \mathrm{~b}$ and c), dense and highly aligned $\mathrm{TiO}_{2}$ nanorod arrays are formed on FTO substrates, with the film thickness of $2 \mu \mathrm{m}$ (Fig. S7a). Fig. 3c indicates the successful deposition of $\mathrm{Bi}_{2} \mathrm{WO}_{6}$ nanoparticles onto the surface of $\mathrm{TiO}_{2}$ nanorods (Fig. S7b). In the HR-TEM image of a typical nanoparticle (Fig. 3d), the lattice space of $0.27 \mathrm{~nm}$ is consistent with the (200) facets of $\mathrm{Bi}_{2} \mathrm{WO}_{6}$.

The band alignment of $\mathrm{TiO}_{2} / \mathrm{Bi}_{2} \mathrm{WO}_{6}$ heterostructures was firstly studied by valence band (VB) XPS and Mott-Schottky measurements. In Fig. 4a, the valence band maximum (VBM) of $\mathrm{TiO}_{2}$ and $\mathrm{L}^{-} \mathrm{O}_{\mathrm{v}}-\mathrm{Bi}_{2} \mathrm{WO}_{6}$ are determined to be 2.1 and $2.4 \mathrm{eV}$, respectively. Based on the MottSchottky plots in Fig. $4 \mathrm{~b}$, the flat band potentials $\left(\mathrm{V}_{\mathrm{fb}}\right)$ of $\mathrm{TiO}_{2}$ and $\mathrm{Bi}_{2} \mathrm{WO}_{6}$ are calculated to be -0.65 and $-0.41 \mathrm{~V}$ vs. $\mathrm{Ag} / \mathrm{AgCl}$. Considering the bandgap of 3.05 and $2.75 \mathrm{eV}$ for $\mathrm{TiO}_{2}$ and $\mathrm{Bi}_{2} \mathrm{WO}_{6}$, more positive conduction band minimum (CBM) is achieved for $\mathrm{L}^{-} \mathrm{O}_{\mathrm{v}}-\mathrm{Bi}_{2} \mathrm{WO}_{6}$. The formation of inverse Type II band alignment is well confirmed by the firstprinciples calculation results in Fig. S8 [32].

The impact of heterostructure formation on the interfacial structure of $\mathrm{TiO}_{2} / \mathrm{L}-\mathrm{O}_{\mathrm{v}}-\mathrm{Bi}_{2} \mathrm{WO}_{6}$ was comprehensively investigated. The formation of two distinct slops in the Mott-Schottky plot of $\mathrm{R}-\mathrm{TiO}_{2} / \mathrm{Bi}_{2} \mathrm{WO}_{6}$ indicates the existence of partial ionized surface states under applied potential (Fig. 5a) [33,34]. Furthermore, the interfacial energy states is substantially influenced by the phase structure of $\mathrm{TiO}_{2}$, as evidenced by the shifted intercept of anatase $\mathrm{TiO}_{2}\left(\mathrm{~A}-\mathrm{TiO}_{2}\right)$ deposited heterostructures (Fig. S9). ESR results in Fig. 5b clearly verify the spontaneous formation of defective interfaces in the heterostructures. Compared to blank $\mathrm{TiO}_{2}$ and $\mathrm{L}-\mathrm{O}_{\mathrm{v}}-\mathrm{Bi}_{2} \mathrm{WO}_{6}, \mathrm{R}-\mathrm{TiO}_{2} / \mathrm{Bi}_{2} \mathrm{WO}_{6}$ exhibits intense paramagnetic signal with $g$ value of 1.996 , which can be ascribed to oxygen vacancies in oxides. Due to the formation of defect-induced surface species (such as $\cdot \mathrm{O}_{2}^{-}$), (R/A)- $\mathrm{TiO}_{2} / \mathrm{Bi}_{2} \mathrm{WO}_{6}$ possesses broad ESR signal, indicating the facilitated formation of oxygen vacancies around $\mathrm{A}-\mathrm{TiO}_{2} / \mathrm{Bi}_{2} \mathrm{WO}_{6}$ interfaces [35].

XPS measurements were carried out to investigate the influence of defect formation on the electronic structure of heterostructures. In the Ti $2 \mathrm{p}$ spectrum of rutile $\mathrm{TiO}_{2} / \mathrm{Bi}_{2} \mathrm{WO}_{6}$ heterostructures (Fig. $5 \mathrm{c}$ ), the rightward shift of Ti $2 \mathrm{p}_{3 / 2}$ peak $\left(458.1 \mathrm{eV}\right.$ ) with respect to pristine $\mathrm{TiO}_{2}$ $(458.5 \mathrm{eV})$ demonstrates the reduction of $\mathrm{Ti}^{4+}$ into $\mathrm{Ti}^{3+}$ caused by oxygen vacancies [36]. Meanwhile, the formation of defective $\mathrm{Bi}_{2} \mathrm{WO}_{6}$ is supported by the co-existence of $\mathrm{W}^{6+}$ and $\mathrm{W}^{5+}$ oxidation states in the core-level W4f spectrum (Fig. 5d) [37]. The simultaneous formation of oxygen vacancies in $\mathrm{TiO}_{2}$ and $\mathrm{Bi}_{2} \mathrm{WO}_{6}$ suggests the complicated interfacial interactions in the heterostructures. Different chemical states of component elements are detected in $\left(\mathrm{R} / \mathrm{A}-\mathrm{TiO}_{2}\right) / \mathrm{Bi}_{2} \mathrm{WO}_{6}$, which is in accordance with the Mott-Schottky and ESR results. The slight shift of Ti $2 \mathrm{p}_{3 / 2}$ peak (Fig. S10a) and the relatively higher content of $\mathrm{W}^{5+}$ (Fig. S10b) demonstrate that electrons caused by interfacial oxygen vacancies are more prone to distributing on $\mathrm{Bi}_{2} \mathrm{WO}_{6}$.

The influence of $\mathrm{TiO}_{2}$ phase structure on the distribution of oxygen vacancies was thereafter simulated by first principles calculations (Fig. S11). For the atomic-level understanding of $\mathrm{O}_{\mathrm{v}}$ formation, different sites in $\mathrm{A} / \mathrm{R}-\mathrm{TiO}_{2} / \mathrm{Bi}_{2} \mathrm{WO}_{6}$ heterostructures are considered. The formation energies of $\mathrm{O}_{\mathrm{v}}$ can be clearly divided into $\mathrm{TiO}_{2}$ sides, $\mathrm{Bi}_{2} \mathrm{WO}_{6}$ sides and interface region, respectively (Fig. 6). The formation trends of oxygen vacancies between $\mathrm{R}-\mathrm{TiO}_{2} / \mathrm{Bi}_{2} \mathrm{WO}_{6}$ and $\mathrm{A}-\mathrm{TiO}_{2} / \mathrm{Bi}_{2} \mathrm{WO}_{6}$ interfaces are obviously different, which is in consistent with the experimental observations. Generally, $\mathrm{O}_{v}$ formation energies in $\mathrm{A}-\mathrm{TiO}_{2}$ sides and interface region are quite close for different positions in $\mathrm{A}-\mathrm{TiO}_{2} / \mathrm{Bi}_{2} \mathrm{WO}_{6}$ heterostructures. Meanwhile, the formation of oxygen vacancies in $\mathrm{Bi}_{2} \mathrm{WO}_{6}$ sides seems to be more stable than interface region. Differently, $\mathrm{O}_{\mathrm{v}}$ formation 

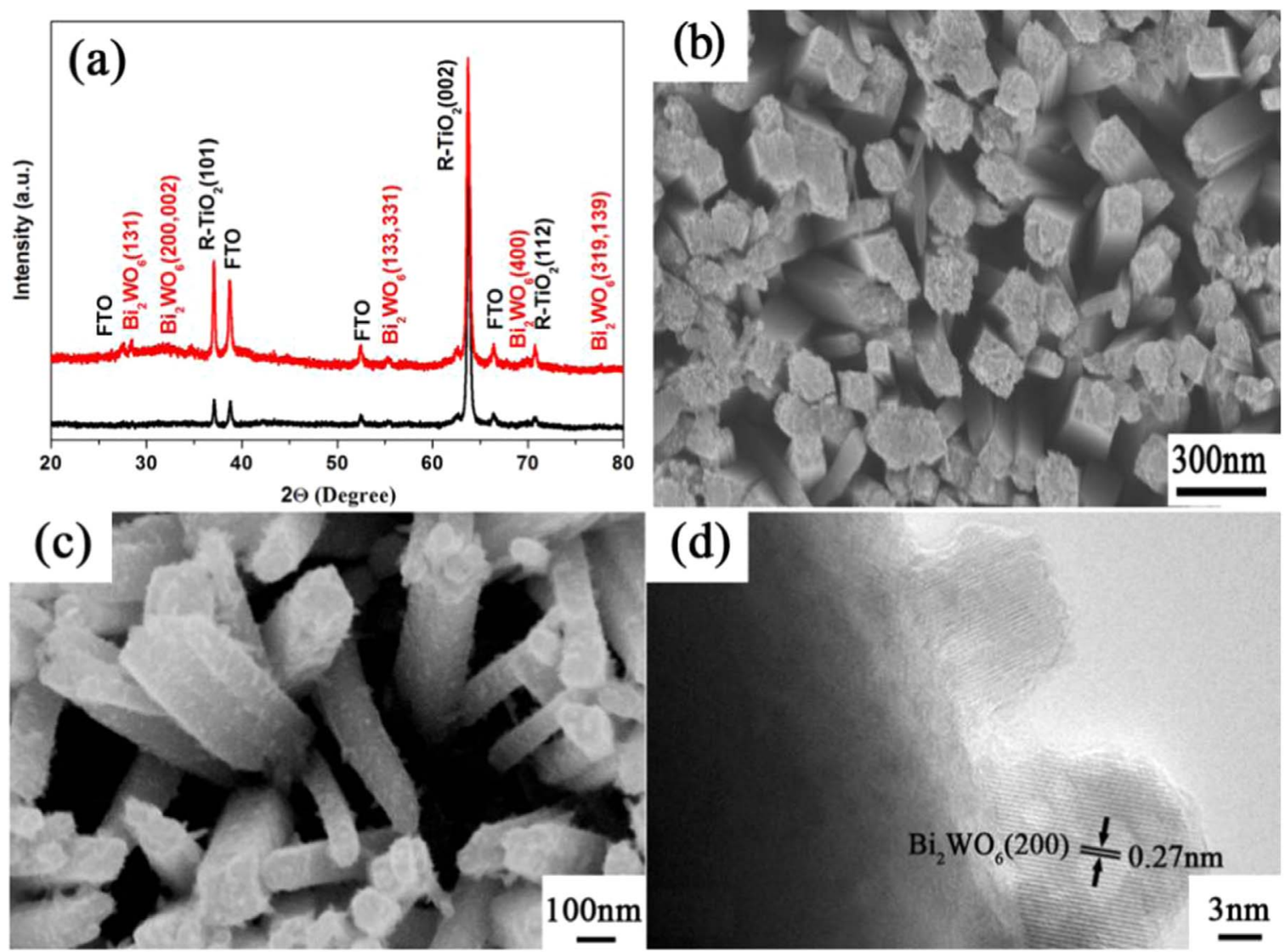

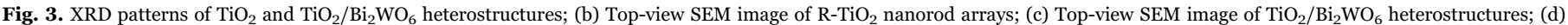
HR-TEM image of $\mathrm{TiO}_{2} / \mathrm{Bi}_{2} \mathrm{WO}_{6}$ heterostructures.

energies in $\mathrm{R}^{-\mathrm{TiO}_{2}}$ monotonically increases from $3.24 \mathrm{eV}$ to $5.42 \mathrm{eV}$, when the position moves from $\mathrm{R}-\mathrm{TiO}_{2}$ sides towards the interface region. Based on the minimum formation energy of $4.1 \mathrm{eV}$, interface region of $\mathrm{Bi}_{2} \mathrm{WO}_{6}$ should be the preferential location for defect formation. Note that $\mathrm{R}-\mathrm{TiO}_{2}$ in $\mathrm{R}-\mathrm{TiO}_{2} / \mathrm{Bi}_{2} \mathrm{WO}_{6}$ heterostructures exhibits relatively larger $\mathrm{O}_{\mathrm{v}}$ formation energy than $\mathrm{Bi}_{2} \mathrm{WO}_{6}$ sides, the migration of $\mathrm{O}_{\mathrm{v}}$ from the $\mathrm{Bi}_{2} \mathrm{WO}_{6}$ side to the $\mathrm{TiO}_{2}$ side is thermodynamically unfavorable. This blocking effect is beneficial for retaining high concentration of $\mathrm{O}_{\mathrm{v}}$ around the heterostructured interfaces. As a result, the sufficient exposure of reactive sites in $\mathrm{Bi}_{2} \mathrm{WO}_{6}$ can promote the transfer of electrons from $\mathrm{Bi}_{2} \mathrm{WO}_{6}$ to $\mathrm{TiO}_{2}$. $[38,39]$ Thus, our theoretical investigation fundamentally demonstrates the specific distribution modulation of oxygen vacancies in depth level through controlling phase structures. This result is also consistent with

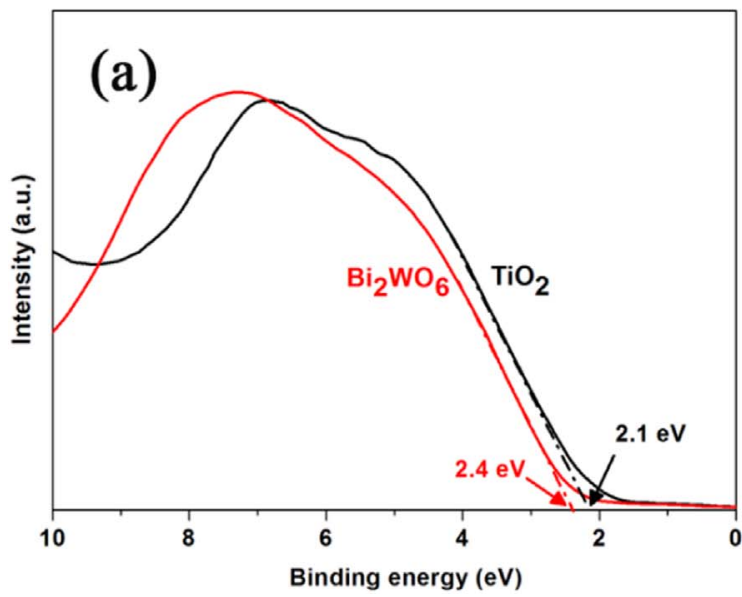

the recent reports that adsorption behavior and surface reactivity of semiconductors can be significantly influenced by the distribution of oxygen vacancies. $[40,41]$ Thus, it is expected that our strategy of defect modulating could provide a new paradigm for boosting PEC performance of heterostructured photoelectrodes. $[42,43]$.

\subsection{Oxygen vacancy boosted photoelectrochemical activity of heterostructures}

PEC water splitting was carried out to evaluate the significant impact of oxygen vacancy modulation on the performance of $\mathrm{TiO}_{2} /$ $\mathrm{Bi}_{2} \mathrm{WO}_{6}$ heterostructures. Compared to blank $\mathrm{TiO}_{2}$, the deposition of $\mathrm{Bi}_{2} \mathrm{WO}_{6}$ can obviously improve the photoresponse of photoanodes in

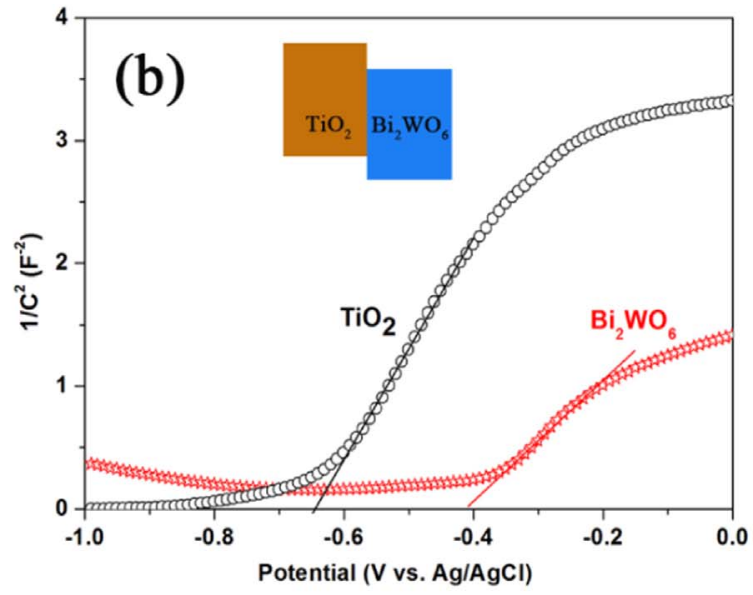

Fig. 4. (a) VB XPS of $\mathrm{TiO}_{2}$ and $\mathrm{Bi}_{2} \mathrm{WO}_{6}$ photocatalysts; (b) Mott-Schottky plots of rutile $\mathrm{TiO}_{2}$ and $\mathrm{Bi}_{2} \mathrm{WO}_{6}$ photocatalysts. 

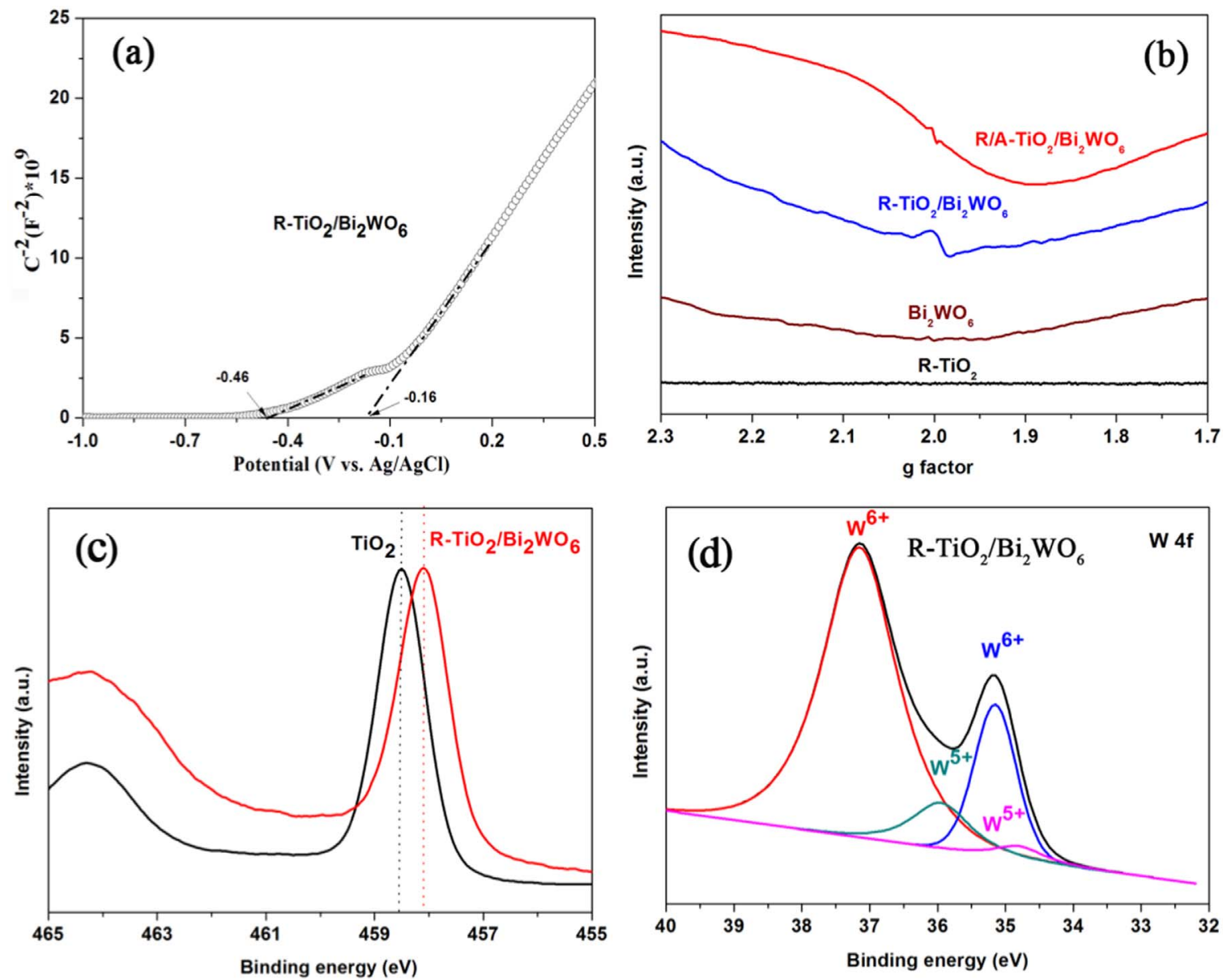

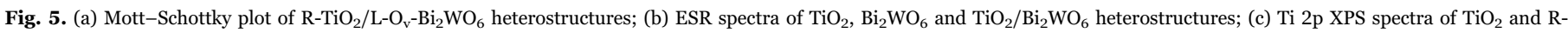
$\mathrm{TiO}_{2} / \mathrm{Bi}_{2} \mathrm{WO}_{6}$; (d) W4f XPS spectrum of $\mathrm{R}-\mathrm{TiO}_{2} / \mathrm{Bi}_{2} \mathrm{WO}_{6}$.

the linear sweep voltammetry (LSV) curves (Fig. 7a). Importantly, the current density of heterostructures is highly dependent on the concentration of intrinsic vacancy defects in $\mathrm{Bi}_{2} \mathrm{WO}_{6}$. $\mathrm{R}-\mathrm{TiO}_{2} / \mathrm{L}-\mathrm{O}_{\mathrm{v}^{-}}$ $\mathrm{Bi}_{2} \mathrm{WO}_{6}$ exhibits the highest $\mathrm{PEC}$ response at $1.0 \mathrm{~V}$ vs. $\mathrm{Ag} / \mathrm{AgCl}$, which is about 3 times higher than that of pristine $\mathrm{TiO}_{2}$. In contrast, only slightly improved photoactivity is achieved for $\mathrm{TiO}_{2} / \mathrm{H}-\mathrm{Ov}-\mathrm{Bi}_{2} \mathrm{WO}_{6}$ heterostructures, indicating the negative contribution of intrinsic oxygen vacancies in $\mathrm{Bi}_{2} \mathrm{WO}_{6}$ to $\mathrm{PEC}$ performance.

Besides intrinsic defects in $\mathrm{Bi}_{2} \mathrm{WO}_{6}$, interfacial oxygen vacancies also present significant influence on the charge separation behaviors. As expected, $\mathrm{R}-\mathrm{TiO}_{2} / \mathrm{L}-\mathrm{O}_{\mathrm{v}}-\mathrm{Bi}_{2} \mathrm{WO}_{6}$ exhibits obviously superior photoactivity than $\left(\mathrm{R} / \mathrm{A}-\mathrm{TiO}_{2}\right) / \mathrm{Bi}_{2} \mathrm{WO}_{6}$ heterostructures (Fig. 7b). It further confirms the beneficial role of oxygen vacancies spontaneously formed in the $\mathrm{TiO}_{2}$ side and around the interface region of $\mathrm{Bi}_{2} \mathrm{WO}_{6}$. Having revealed the fundamental strategy of defect modulation, facile vacuum treatment process was finally used to facilitate the formation of interfacial oxygen vacancies. When vacuum-treated rutile nanorods $\left(\mathrm{O}_{\mathrm{v}}-\mathrm{TiO}_{2}\right)$ was used to construct heterostructured photoanodes, unprecedented photocurrent density of $1.58 \mathrm{~mA} / \mathrm{cm}^{2}$ can be readily achieved. It indicates that PEC performance of photoanodes can be rationally boosted by inhibiting the intrinsic defects and simultaneously promoting the interfacial oxygen vacancies with modulated depth distribution.

Based on the above results, the mechanism of oxygen vacancy modulation in the heterostructured photoanodes is illustrated in Scheme 1. In the PEC water splitting devices, holes migrate to the photoanode surface to drive interfacial oxidation reaction, whilst electrons are transferred to the counter electrode to drive the reduction reaction. In order to achieve efficient charge separation, it is essential to facilitate the electron transfer to $\mathrm{TiO}_{2}$ matrix and then electrodes. The neutral or positive nature of oxygen vacancies can significantly influence the charge balance and charge mobility over the heterostructured interfaces. For the requirement of optimizing charge transfer pathways through decreasing interfacial energy barriers, it is reasonable to suppress the formation of intrinsic oxygen vacancies in $\mathrm{W}-\mathrm{O}-\mathrm{W}$ layers of $\mathrm{Bi}_{2} \mathrm{WO}_{6}$ and simultaneously generate more oxygen vacancies in $\mathrm{TiO}_{2}$. The distribution of interfacial oxygen vacancies exhibits remarkable impact on the behavior of interfacial charge transfer. The presence of oxygen vacancies in the interface region of $\mathrm{Bi}_{2} \mathrm{WO}_{6}$ is beneficial for the migration of electrons from $\mathrm{Bi}_{2} \mathrm{WO}_{6}$ to $\mathrm{TiO}_{2}$ through interfacial re-equilibrium, while those distributed in the $\mathrm{TiO}_{2}$ side tend to migrate toward conducting skeleton. Furthermore, recent studies have also demonstrated that diminished interfacial oxygen vacancies in $\mathrm{TiO}_{2}$ is beneficial for the formation of bridged water molecules, which could efficiently trap photogenerated holes for photooxidation reactions. [4446] It is reasonably believed that the superior electron transfer and hole trapping abilities undoubtedly result in the significantly improved photoactivity of $\mathrm{R}-\mathrm{TiO}_{2} / \mathrm{Bi}_{2} \mathrm{WO}_{6}$ heterostructures for photoelectrochemical water splitting. In contrast, the competitive capture of extra electrons by adsorbed oxygen molecules is unavoidable when oxygen vacancies are located in the interface region of $\mathrm{A}-\mathrm{TiO}_{2}$, also known as oxygen activation reactions. [47] Due to the favorable formation of oxygen vacancies in the $\mathrm{Bi}_{2} \mathrm{WO}_{6}$ side, the relatively lower concentration of interfacial defects is ascribed to the poor charge separation in $\mathrm{A}-\mathrm{TiO}_{2} / \mathrm{Bi}_{2} \mathrm{WO}_{6}$ heterostructures. Thus, PEC performance of heterostructures can be definitely boosted through modulating the distribution of intrinsic and interfacial defects in non-stoichiometric semiconductors. The great contribution of oxygen vacancy modulation on the photoactivity is well evidenced by the deteriorated performance of aircalcined heterostructures (Fig. S12), with eliminated oxygen vacancies in 

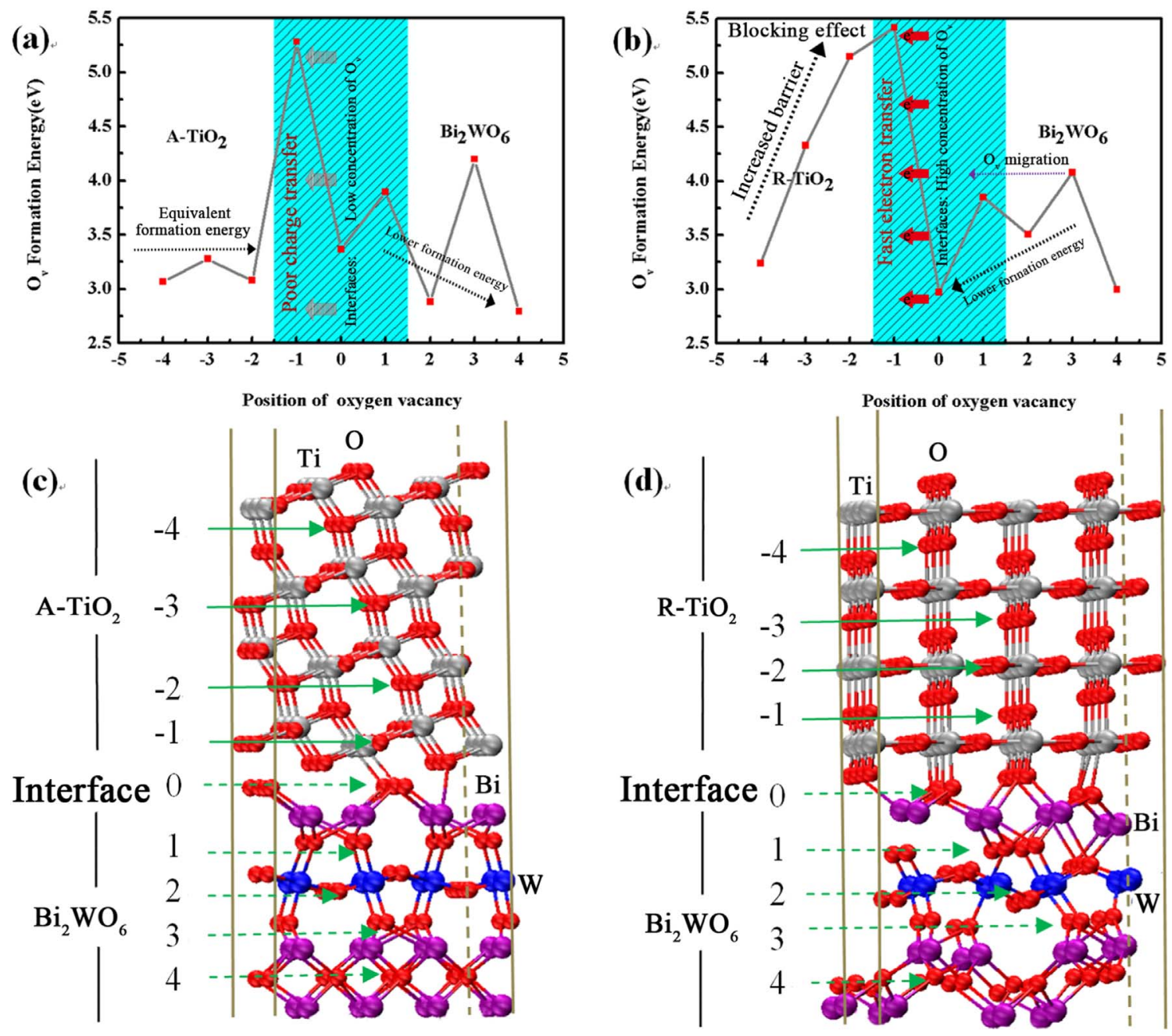

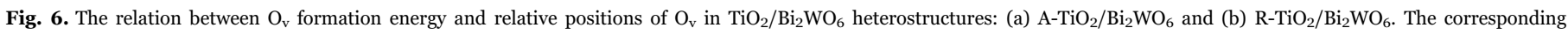

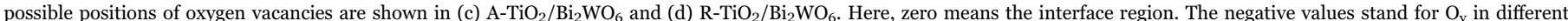

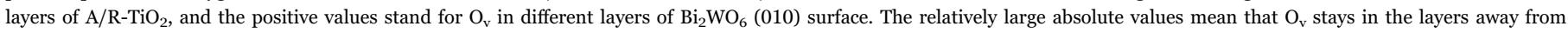

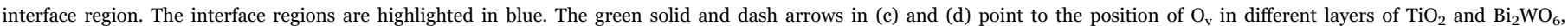
respectively.
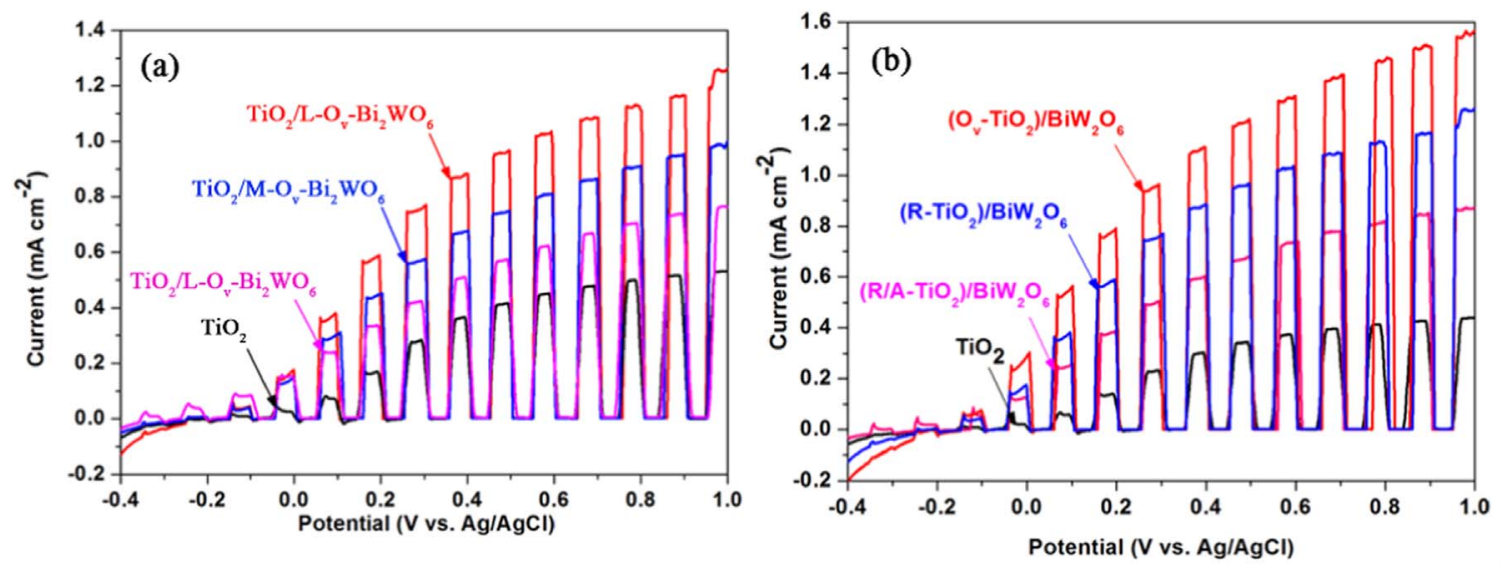

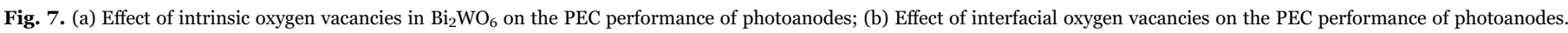

semiconductors. It should point out that the significant contribution of depth distribution of $\mathrm{O}_{\mathrm{v}}$ to the photocatalytic activities of other heterostructured semiconductors was also observed, which further evidenced the applicability of our defect modulation strategy. The corresponding results will be reported in our following papers.

\section{Conclusion}

In summary, $\mathrm{TiO}_{2} / \mathrm{Bi}_{2} \mathrm{WO}_{6}$ heterostructures with facilely controlled interfacial electronic structures were used to demonstrate the principle of interfacial oxygen vacancy modulation of heterostructured photo- 


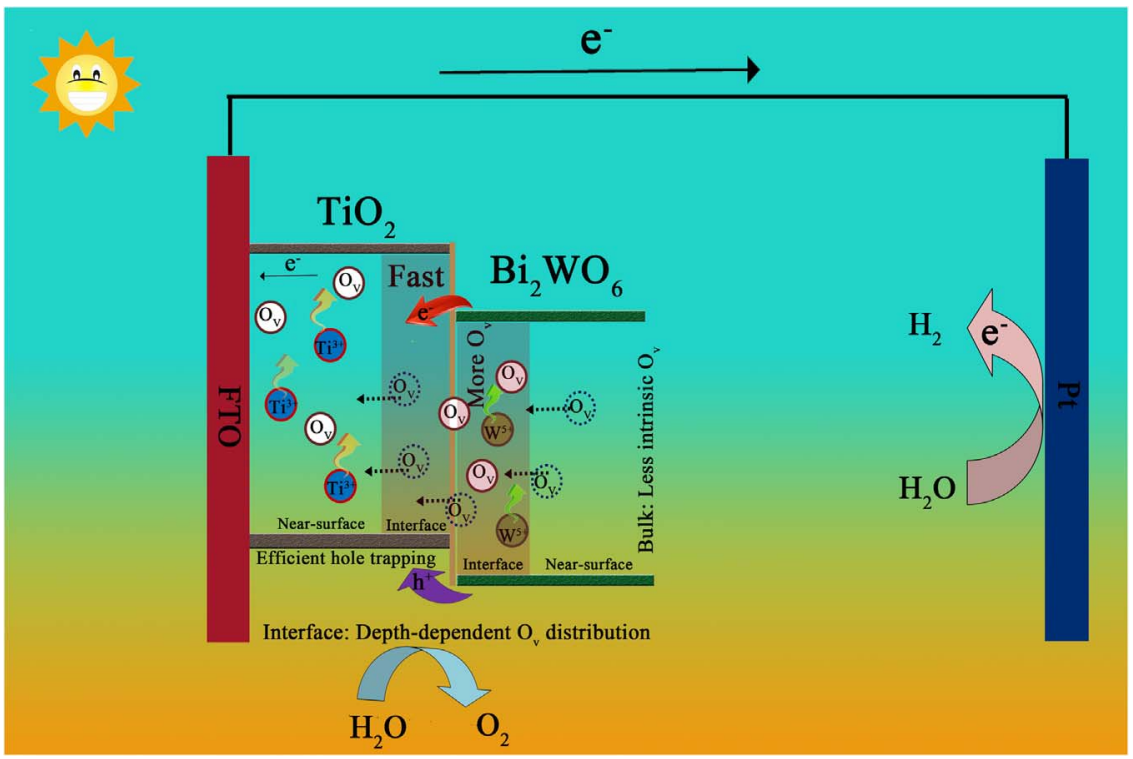

Scheme 1. Band diagram and mechanism of oxygen vacancy modulation in $\mathrm{TiO}_{2} / \mathrm{Bi}_{2} \mathrm{WO}_{6}$ heterostructures.

electrodes. Both experimental observations and theoretical calculations indicate that the consecutive transfer of electrons from $\mathrm{Bi}_{2} \mathrm{WO}_{6}$ to $\mathrm{TiO}_{2}$ and then electrodes could be facilitated by suppressing intrinsic oxygen vacancies in $\mathrm{Bi}_{2} \mathrm{WO}_{6}$ and simultaneously increasing those in $\mathrm{TiO}_{2}$. A comprehensive study evidenced that the distribution of oxygen vacancies in depth level played a crucial role in determining the pathways of charge collection in heterostructured photoanodes. Oxygen vacancies around the interface region of $\mathrm{Bi}_{2} \mathrm{WO}_{6}$ and in the $\mathrm{TiO}_{2}$ side is beneficial for the substantial migration of electrons toward conducting substrates. The strategy of oxygen vacancy modulation resulted in unprecedented photocurrent density of $1.58 \mathrm{~mA} / \mathrm{cm}^{2}$, which is more than 4 times higher than pristine $\mathrm{TiO}_{2}$. Our research can serve as a versatile approach to bridge heterostructure design with defect control by modulating the local distribution of oxygen vacancies.

\section{Acknowledgments}

This work was supported by the National Natural Science Foundation of China (Grant No. 51438011, 51572016 and U1530401). The computation supports from Tianhe-2JK computing time award at the Beijing Computational Science Research Center (CSRC) and the Special Program for Applied Research on Super Computation of the NSFC-Guangdong Joint Fund (the second phase) were also acknowledged. This work was also supported by the National Key R\&D Program of China (Grant No. 2016YFC0400502 and 2016YFB0700700).

Dr. Xiaoqiang An and Dr. Le Zhang contributed equally to this work.

\section{Appendix A. Supporting information}

Supplementary data associated with this article can be found in the online version at doi:10.1016/j.nanoen.2017.04.002.

\section{References}

[1] T. Hisatomi, J. Kubota, K. Domen, Chem. Soc. Rev. 43 (2014) 7520-7535.

[2] N. Lewis, Science 351 (2016) 353.

[3] H. Li, Y. Zhou, W. Tu, J. Ye, Z. Zou, Adv. Func. Mater. 25 (2015) 998-1013.

[4] P. Zhou, J. Yu, M. Jaroniec, Adv. Mater. 26 (2014) 4920-4935.

[5] J. Hou, C. Yang, H. Cheng, S. Jiao, O. Takeda, H. Zhu, Energy Environ. Sci. 7 (2014) 3758-3768.
[6] M. Rahman, S. Bazargan, S. Srivastava, X. Wang, M. Abd-Ellah, J. Thomas, N. Heinig, D. Pradhan, K. Leung, Energy Environ. Sci. 8 (2015) 3363-3373.

[7] R. Liu, Z. Zheng, J. Spurgeona, X. Yang, Energy Environ. Sci. 7 (2014) 2504-2517.

[8] S. Moniz, S. Shevlin, D. Martin, Z. Guo, J. Tang, Energy Environ. Sci. 8 (2015) $731-759$.

[9] K. Wu, H. Zhu, Z. Liu, W. Rodríguez-Córdoba, T. Lian, J. Am. Chem. Soc. 134 (2012) 10337-10340.

[10] P. Winget, L. Schirra, D. Cornil, H. Li, V. Coropceanu, P. Ndione, A. Sigdel, D. Ginley, J. Berry, J. Shim, H. Kim, B. Kippelen, J. Brédas, O. Monti, Adv. Mater. 26 (2014) 4711-4716.

[11] Y. Liu, B. Zhang, L. Luo, X. Chen, Z. Wang, E. Wu, D. Su, W. Huang, Angew. Chem. Int. Ed. 54 (2015) 15260-15265.

[12] F. Lei, Y. Sun, K. Liu, S. Gao, L. Liang, B. Pan, Y. Xie, J. Am. Chem. Soc. 136 (2014) 6826-6829.

[13] Z. Zhang, J. Jr, Chem. Rev. 112 (2012) 5520-5551.

[14] A. Cowan, J. Durrant, Chem. Soc. Rev. 42 (2013) 2281-2293.

[15] C. Kronawitter, J. Bakke, D. Wheeler, W. Wang, C. Chang, B. Antoun, J. Zhang, J. Guo, S. Bent, S. Mao, L. Vayssieres, Nano Lett. 11 (2011) 3855-3861.

[16] X. An, T. Li, B. Wen, J. Tang, Z. Hu, L. Liu, J. Qu, C. Huang, H. Liu, Adv. Energ. Mater. 6 (2016). http://dx.doi.org/10.1002/aenm.201502268.

[17] I. Cho, H. Han, M. Logar, J. Park, X. Zheng, Adv. Energy Mater. 5 (2015) 1501840.

[18] I. Beinik, M. Hellstrom, T. Jensen, P. Broqvist, J. Lauritsen, Nat. Commun. 6 (2015) 8845.

[19] B. Veal, S. Kim, P. Zapol, H. Iddir, P. Baldo, J. Eastman, Nat. Commun. 7 (2015) 11892.

[20] J. VandeVondele, M. Krack, F. Mohamed, M. Parrinello, T. Chassaing, J. Hutter, Comput. Phys. Commun. 167 (2005) 103-128.

[21] J.P. Perdew, K. Burke, M. Ernzerhof, Phys. Rev. Lett. 77 (1996) 3865-3868.

[22] B.J. Morgan, G.W. Watson, Surf. Sci. 601 (2007) 5034-5041.

[23] S. Goedecker, M. Teter, J. Hutter, Phys. Rev. B 54 (1996) 1703-1710.

[24] J. VandeVondele, J. Hutter, J. Chem. Phys. 127 (2007) 114105-114114.

[25] Y. Li, Z. Tang, J. Zhang, Z. Zhang, J. Phys. Chem. C 120 (2016) 9750-9763.

[26] K. Xie, N. Umezawa, N. Zhang, P. Reunchan, Y. Zhang, J. Ye, Energy Environ. Sci. 4 (2011) 4211-4219.

[27] Y. Zhao, G. Chen, T. Bian, C. Zhou, G. Waterhouse, L. Wu, C. Tung, L. Smith, D. O'Hare, T. Zhang, Adv. Mater. 27 (2015) 7824-7831.

[28] Z. Nie, D. Ma, G. Fang, W. Chen, S. Huang, J. Mater. Chem. A 4 (2016) 24382444.

[29] X. Chen, L. Liu, P. Yu, S. Mao, Science 331 (2011) 746-750.

[30] J. Tian, Y. Sang, G. Yu, H. Jiang, X. Mu, H. Liu, Adv. Mater. 25 (2013) 5075-5080.

[31] T. Jing, Y. Dai, W. Wei, X. Ma, B. Huang, Phys. Chem. Chem. Phys. 16 (2014) $18596-18604$

[32] Y. Hou, S. Liu, J. Zhang, X. Cheng, Y. Wang, Dalton Trans. 43 (2014) 1025-1031.

[33] M. Huijben, G. Koster, M. Kruize, S. Wenderich, J. Verbeeck, S. Bals, E. Slooten, B. Shi, H. Molegraaf, J. Kleibeuker, S. Aert, J. Goedkoop, A. Brinkman, D. Blank, M. Golden, G. Tendeloo, H. Hilgenkamp, G. Rijnders, Adv. Funct. Mater. 23 (2013) 5240-5248.

[34] M. Metikos-Hukovic, S. Omanovic, A. Jukic, Electrochim. Acta 45 (1999) 977-986.

[35] A. Giannakas, M. Antonopoulou, Y. Deligiannakis, I. Konstantinou, Appl. Catal. BEnviron. 140- 141 (2013) 636-645.

[36] J. Chen, W. Song, H. Hou, Y. Zhang, M. Jing, X. Jia, X. Ji, Adv. Func. Mater. 25 (2015) 6793-6801. 
[37] G. Wang, Y. Ling, H. Wang, X. Yang, C. Wang, J. Zhang, Y. Li, Energy Environ. Sci. 5 (2012) 6180-6187.

[38] S. Wendt, J. Matthiesen, R. Schaub, K. Vestergaard, E. Lægsgaard, F. Besenbacher, B. Hammer, Phys. Rev. Lett. 96 (2006) 066107.

[39] C. Valentin, G. Pacchioni, A. Selloni, Phys. Rev. Lett. 97 (2006) 166803.

[40] X. Lang, Y. Liang, L. Sun, S. Zhou, W. Lau, J. Phys. Chem. C Doi: http://dx.doi.org/ 10.1021/acs.jpcc.6b11356.

[41] J. Fan, C. Li, J. Zhao, Y. Shan, H. Xu, J. Phys. Chem. C 120 (2016) 27917-27924.

[42] M. Setvín, U. Aschauer, P. Scheiber, Y. Li, W. Hou, M. Schmid, A. Selloni, U. Diebold, Science 341 (2013) 988-990.

[43] D. Herlihy, M. Waegele, X. Chen, C.D. Pemmaraju, D. Prendergast, T. Cuk, Nat. Chem. 8 (2016) 549-555.

[44] K. Shirai, T. Sugimoto, K. Watanabe, M. Haruta, H. Kurata, Y. Matsumoto, Nano Lett. 16 (2016) 1323-1327.

[45] H. Hussain1, G. Tocci, T. Woolcot, X. Torrelles, C.L. Pang, D.S. Humphrey, C.M. Yim, D.C. Grinter, G. Cabailh, O. Bikondoa, R. Lindsay, J. Zegenhagen, A. Michaelides, G. Thornton, Nat. Mater. (2016). http://dx.doi.org/10.1038/ nmat4793.

[46] S. Selcuk, A. Selloni, Nat. Mater. 15 (2016) 1107-1112.

[47] N. Zhang, X. Li, Hg Ye, S. Chen, H. Ju, D. Liu, Y. Lin, W. Ye, C. Wang, Q. Xu, J. Zhu, L. Song, J. Jiang, Y. Xiong, J. Am. Chem. Soc. 138 (2016) 8928-8935.

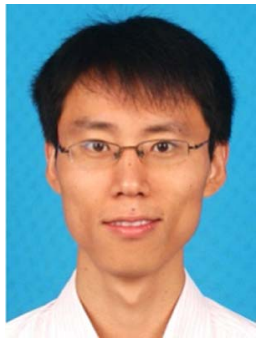

Xiaoqiang An graduated from the Department of Fire Engineering of Chinese People's Armed Police Force Academy in 2003. He obtained his Ph.D degree from Beijing Institute of Technology in 2008. After that, he conducted his postdoctoral research at the Chinese University of Hong Kong and University College London, in the period of 2011-2014. Currently, he is an associate professor in Research Center for Eco-Environmental Sciences, Chinese Academy of Sciences. His main research interests focus on solar-driven photocatalytic materials for environmental remediation and renewable energy applications.

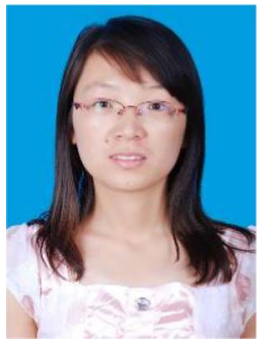

Le Zhang received her B.S. in applied physics from Shandong University in 2013. Now she is a Ph.D candidate at Beijing Computational Science Research Center. Her research is focused on the first principles calculations on materials of photoelectric catalysis.

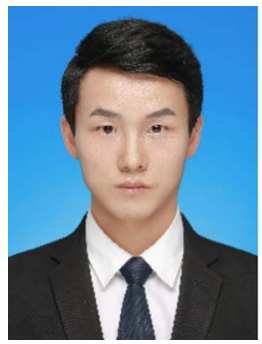

o Wen received his B.S. in applied physics from Tianjin University in 2012. Now as a Ph.D candidate, he is studying at Beijing Computational Science Research Center and Peking University. His interest is mainly at the electronic property of photoelectric catalysis (such as $\mathrm{TiO}_{2}$ ).

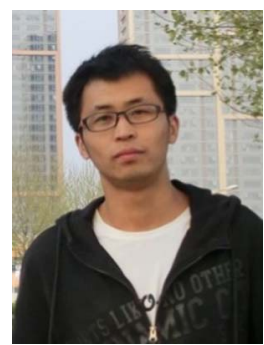

Zhenao Gu is currently a Ph.D. candidate at Research Center for Eco-Environmental Sciences (RCEES), Chinese Academy of Sciences (CAS). His research interests focus on the interfacial design of low-cost metal oxide photocatalysts and photoanodes for efficient solar energy conversion and environmental remediation.

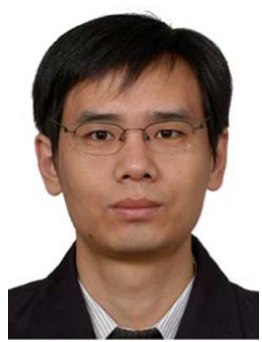

Li-Min Liu received his Ph.D. degree in materials science from the Institute of Metal Research, Chinese Academy of Sciences, in 2006. During his Ph.D. study, he visited Queen's University Belfast for one year. Then he worked at the Fritz Haber Institute, University College London and Princeton University. Since 2012, he works at the Beijing Computational Science Research Center. He has coauthored more than 100 journal papers. He was granted"1000-plan for the young talent" and "the National Science Fund for Excellent Young Scholars". His research interests focus on photocatalysis and aqueous water-solid interfaces for electrocatalysis and fuel cells.

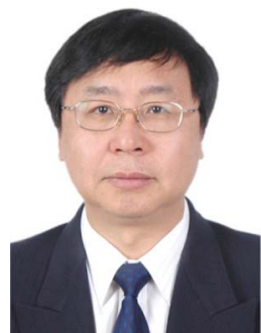

Jiuhui Qu received his Ph.D degree from Harbin Institute of Technology in 1992, and continued his postdoctora research there. In 1994, he joined Research Center for Ecological and Environmental Sciences (RCEES), Chinese Academy of Science. He has been an Academician of the Chinese Academy of Engineering since 2009. He serves/ served as Vice President of the All-China Environment Federation, Member of the National Environmental Advisory Committee and Board Director of the International Water Association (IWA). Dr. Qu's research interests include water pollution control, particularly development of the theories, technologies, and engineering applications relating to drinking water quality and safety.

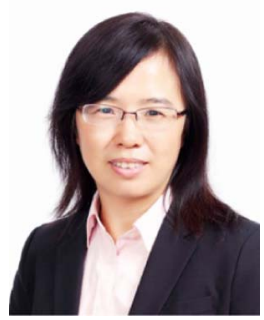

Huijuan Liu received her Ph.D degree from the Chinese Academy of Sciences (CAS) in 2003. She is now a full professor of the Research Center for Eco-Environmental Sciences, CAS. She was granted the National Science Fund for Distinguished Young Scholars of China in 2012. Her research interests focus on the water purifying principle and technology of adsorption, coagulation, photo- and electrochemical processes. 